\title{
Saccharomyces cerevisiae Rhodanese RDL2 Uses the Arg Residue of the Active-Site Loop for Thiosulfate Decomposition
}

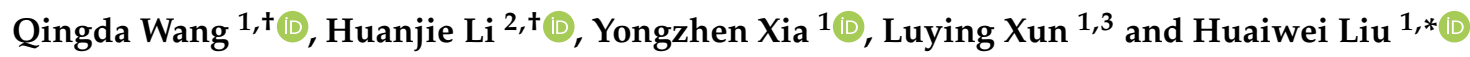 \\ 1 State Key Laboratory of Microbial Technology, Shandong University, Qingdao 266237, China; \\ wangqingda@mail.sdu.edu.cn (Q.W.); xiayongzhen2002@sdu.edu.cn (Y.X.); \\ luying_xun@vetmed.wsu.edu (L.X.) \\ 2 School of Medicine, Cheeloo College of Medicine, Shandong University, Jinan 260024, China; \\ lihuanjie@sdu.edu.cn \\ 3 Department of Chemistry, School of Molecular Biosciences, Washington State University, \\ Pullman, WA 99164-4630, USA \\ * Correspondence: liuhuaiwei@sdu.edu.cn; Tel.: +81-532-5863-1572 \\ + These authors contribute equally to this study.
}

check for updates

Citation: Wang, Q.; Li, H.; Xia, Y.; Xun, L.; Liu, H. Saccharomyces cerevisiae Rhodanese RDL2 Uses the Arg Residue of the Active-Site Loop for Thiosulfate Decomposition. Antioxidants 2021, 10, 1525. https:// doi.org/10.3390/antiox10101525

Academic Editors:

Małgorzata B. Iciek

and Anna Bilska-Wilkosz

Received: 21 August 2021

Accepted: 22 September 2021

Published: 26 September 2021

Publisher's Note: MDPI stays neutral with regard to jurisdictional claims in published maps and institutional affiliations.

Copyright: (c) 2021 by the authors. Licensee MDPI, Basel, Switzerland. This article is an open access article distributed under the terms and conditions of the Creative Commons Attribution (CC BY) license (https:/ / creativecommons.org/licenses/by/ $4.0 /)$.

\begin{abstract}
Persulfide, polysulfide and thiosulfate are examples of sulfane sulfur containing chemicals that play multiple functions in biological systems. Rhodaneses are widely present in all three kingdoms of life, which catalyze sulfur transfer among these sulfane sulfur-containing chemicals. The mechanism of how rhodaneses function is not well understood. Saccharomyces cerevisiae rhodanese 2 (RDL2) is involved in mitochondrial biogenesis and cell cycle control. Herein, we report a $2.47 \AA$ resolution structure of RDL2 co-crystallized with thiosulfate (PDB entry: 6K6R). The presence of an extra sulfur atom $S_{\delta}$, forming a persulfide bond with the $S_{\gamma}$ atom of $C_{y s} s_{106}$, was observed. Distinct from the persulfide groups in GlpE (PDB entry:1GMX) and rhobov (PDB entry:1BOI), the persulfide group of RDL2 is located in a peanut-like pocket of the neutral electrostatic field and is far away from positively charged amino acid residues of its active-site loop, suggesting no interaction between them. This finding suggests that the positively charged amino acid residues are not involved in the stabilization of the persulfide group. Activity assays indicate that the $\operatorname{Arg}_{111}$ of the active-site loop is critical for the sulfane sulfur transfer. In vitro assays indicate that Arg propels the thiosulfate decomposition. Thus, we propose that Arg can offer a hydrogen bond-rich, acidic-like microenvironment in RDL2 in which thiosulfate decomposes to release sulfane sulfur. Thr of the active-site loop of rhodaneses has the same functions as Arg. Our proposal may explain the catalyzing mechanism of rhodaneses.
\end{abstract}

Keywords: rhodanese; crystal structure; thiosulfate; polysulfides; Saccharomyces cerevisiae

\section{Introduction}

Reactive sulfur species (RSS) are a group of sulfur containing compounds commonly existing in biological systems. They are essential to life due to the roles in cell signaling, redox homeostasis, and metabolic regulation [1]. Representative RSS include hydrogen sulfide $\left(\mathrm{H}_{2} \mathrm{~S}\right)$, hydrogen persulfide (HSSH), organic persulfides (RSSH), and polysulfides $\left(\mathrm{HSS}_{\mathrm{n}} \mathrm{H}, \mathrm{RSS}_{\mathrm{n}} \mathrm{H}, \mathrm{RSS}_{\mathrm{n}} \mathrm{R}, n \geq 2\right.$ ). Among them, $\mathrm{H}_{2} \mathrm{~S}$ has been recognized as the third gasotransmitter after carbon monoxide (CO) and nitric oxide (NO) [2]. It exerts various effects including cytoprotection, anti-inflammation, angiogenesis, and vasodilation at low concentrations [3]. However, the chemical mechanisms that $\mathrm{H}_{2} \mathrm{~S}$ signaling remain unclear. Per/polysulfides are oxidation products of $\mathrm{H}_{2} \mathrm{~S}$ that contain one or more zero valent sulfur atoms $\left(\mathrm{S}^{0}\right.$, sulfane sufur). Recent studies indicated that per/polysulfides participate in $\mathrm{H}_{2} \mathrm{~S}$ signaling $[4,5]$.

Different from the chemically labile $\mathrm{H}_{2} \mathrm{~S}$ and per/polysulfides, thiosulfate is quite inert at a neutral and alkaline $\mathrm{pH}$. Its spontaneous oxidation to sulfate takes months and 
decomposition only happens at very acidic $\mathrm{pH}[6,7]$. On the other hand, thiosulfuric acid $\left(\mathrm{H}_{2} \mathrm{~S}_{2} \mathrm{O}_{3}, \mathrm{pK} K_{a 1}=1.74\right.$ and $\left.\mathrm{p} K_{a 2}=0.6\right)$ and its monoanion $\left(\mathrm{HS}_{2} \mathrm{O}_{3}{ }^{-}\right)$are incredibly unstable and easily decompose to sulfane sulfur and sulfite [8]. Previous studies have indicated that the reason for this is that $\mathrm{H}_{2} \mathrm{~S}_{2} \mathrm{O}_{3}$ and $\mathrm{HS}_{2} \mathrm{O}_{3}{ }^{-}$can exist as special isomers in which the negative charged $\mathrm{O}^{-}$is neutralized by $\mathrm{H}^{+}$to allow the formation of the $\mathrm{S}=\mathrm{S}$ bond [9]. The $\mathrm{S}=\mathrm{S}$ bond is scissile and one sulfur atom is easily released as free sulfane sulfur [10]. The released sulfane sulfur is prone to forming a sulfur chain or attaching itself to a nucleophile, making the decomposition reaction irreversible [7].

Thiosulfate exits as anion $\left(\mathrm{S}_{2} \mathrm{O}_{3}{ }^{2-}\right)$ in a physiological $\mathrm{pH}$ range (7.2 7.6). It is usually regarded as a stable sulfane sulfur carrier in biological systems. For instance, the sulfide: quinone oxidoreductase (SQR) and persulfide dioxygenase (PDO) mediated $\mathrm{H}_{2} \mathrm{~S}$ oxidation pathway usually produces sulfite as the final product; however, when RSSH (the product of SQR) is more abundant than the oxidation capability of PDO, sulfite and RSSH can automatically react to produce thiosulfate [11-13]. The fates for produced thiosulfate include being further oxidized to sulfate by the sulfur oxidation system (SOX), exported out of the cell, and decomposed by enzymes. Similarly to per/polysulfides, thiosulfate may also be related to $\mathrm{H}_{2} \mathrm{~S}$ signaling, evidenced by the recent finding that the colonic thiosulfate level is increased during inflammatory conditions [14].

Rhodaneses, or thiosulfate: cyanide sulfurtransferases (E.C. 2.8.1.1) was first found in certain tissues of mammals and defined by the activity of catalyzing the transfer of a sulfane sulfur atom from thiosulfate to cyanide, a reaction for cyanide detoxification (Reaction 1) [15]. Further studies indicated that these enzymes are wildly distributed in all three kingdoms of life and are involved in multiple bioprocesses. For instance, the human rhodanese TST is related to Crohn's disease and is essential for 5S ribosomal RNA import into mitochondria $[16,17]$. The Saccharomyces cerevisiae rhodanese 1 (RDL1) is critical for thiosulfate assimilation through converting thiosulfate to glutathione persulfide (GSSH) (Reaction 2) [18]. According to Reaction 2, Rhodnaese is able to utilize stable thiosulfate to generate reactive sulfane sulfur such as GSSH. Since GSSH is involved in scavenging ROS which is important for maintaining cellular redox homeostasis. It is possible that rhodanese is also involved in the antioxidant processes of cell.

$$
\begin{aligned}
& \mathrm{S}_{2} \mathrm{SO}_{3}{ }^{2-}+\mathrm{CN}^{-} \rightarrow \mathrm{SCN}^{-}+\mathrm{SO}_{3}{ }^{2-} \\
& \mathrm{S}_{2} \mathrm{SO}_{3}{ }^{2-}+\mathrm{GSH} \rightarrow \mathrm{GSSH}+\mathrm{SO}_{3}{ }^{2-}
\end{aligned}
$$

More than a dozen rhodanese structures have been determined by X-ray or NMR methods. They share a universal structural model (rhodanese domain) with an $\alpha / \beta$ topology in which $\alpha$ helices surround a central five-stranded $\beta$-sheet $[19,20]$. The active site is a loop composed of six amino acid residues starting with Cys (the active-site loop) [21,22]. Except for the conserved Cys, the other five amino acid residues are widely distinct in different rhodaneses [23]. A common feature is basic amino acid residues have a high presence frequency in the active-site loop. The rhodanese domain can be present singly, in tandem repeats or fused to other protein modules [23].

Rhodaneses catalyze sulfur transfer reactions with the ping-pong mechanism. First, the sulfane sulfur of thiosulfate or other sulfane sulfur donors is transferred to the thiol group of conserved Cys to form $E S^{0}$, the enzyme-sulfur adduct. Second, $E S^{0}$ transfers the sulfane sulfur to a nucleophilic acceptor, such as cyanide and GSH anions $\left(\mathrm{CN}^{-}\right.$and $\mathrm{GS}^{-}$), and the occupation of Cys thiol is released [23]. Regarding this catalysis mechanism, one question has not been clearly answered: how is sulfane sulfur cut off from thiosulfate? Compared to sulfite anion $\left(\mathrm{SO}_{3}{ }^{2-}\right)$, thiol anion $\left(\mathrm{RS}^{-}\right)$is a weaker nucleophile, hence the sulfane sulfur transfer from thiosulfate to Cys thiol is not chemically preferred, evidenced by the finding that GSSH can spontaneously react with sulfite to produce thiosulfate at neutral $\mathrm{pH}$ and $25^{\circ} \mathrm{C}$; whereas, the reversed reaction rarely happens [11,18]. Rhodanese must have a catalytical way to break the stable S-S bond of thiolsulfate. 
In this study, we determined the 3D structure of S. cerevisiae RDL2, a single-domain rhodanese involved in mitochondrial biogenesis [24] and cell cycle control [25]. Kinetic characterization indicated that RDL2 catalyzes both Reactions 1 and 2. Mutating the last amino acid of its active-site loop $\left(\mathrm{Arg}_{111}\right)$ resulted in loss of the capability of forming $E S^{0}$ intermediate, indicating that $\operatorname{Arg}_{111}$ is essential for breaking S-S bond of thiolsulfate. Further studies suggested that the loop-ending amino acid, mostly Arg or hydroxyl containingThr/Ser [26], commonly plays such roles in rhodaneses. Thus, we proposed a mechanism for explaining how rhodaneses subtract a sulfur from a stable substrate like thiosulfate to form the unstable $E S^{0}$.

\section{Materials and Methods}

\subsection{Strains and Materials}

Escherichia coli BL21(DE3) strain and the pET30a plasmid (purchased from Invitrogen, Shanghai, China) were used for protein expression. Thiosulfate, potassium cyanide, and reduced glutathione (GSH) were purchased from Sigma-Aldrich. Other chemicals used for E. coli cultivation and protein purification were purchased from (Sangon Biotech, Shanghai, China) if not specifically mentioned.

\subsection{Protein Expression and Purification}

The gene encoding RDL2 was amplified from genomic DNA of S. cerevisiae BY4742 as reported previously [27]. The DNA fragment encoding DUF442 domain of CpSQR was amplified from genomic DNA of Cupriavidus pinatubonensis JMP134. The gene encoding TST was codon-optimized for expression in E. coli and synthesized by Beijing Genomics institution (BGI). These genes were ligated with pET30a plasmid using the T5 exonucleasedependent assembly method [28]. A $4 \mu \mathrm{L}$ aliquot of 5X TEDA reaction solution was thawed on ice, and $16 \mu \mathrm{L}$ of DNA solution including the linear pET30a and insert was added. After mixing, the reaction was carried out at $30^{\circ} \mathrm{C}$ for $40 \mathrm{~min}$ and terminated by placing on ice, and the reaction solution was then used for transformation. Mutants of these proteins were constructed using the revised QuikChange ${ }^{\mathrm{TM}}$ method [29].

E. coli BL21(DE3) strains harboring the expression plasmids were incubated in LB medium at $25^{\circ} \mathrm{C}$ with shaking $(225 \mathrm{rpm})$. Kanamycin $(50 \mu \mathrm{g} / \mathrm{mL})$ was added. When $\mathrm{OD}_{600}$ reached to $0.6,0.1 \mathrm{mM}$ isopropyl $\beta$-D-1-thiogalactopyranoside (IPTG) was added to induce the expression, and the temperature was decreased to $16^{\circ} \mathrm{C}$. The cultivation was further continued for $22 \mathrm{~h}$, and then cells were harvested by centrifugation and resuspended in buffer I (20 mM Tris- $\mathrm{HCl}, 0.5 \mathrm{M} \mathrm{NaCl}, 20 \mathrm{mM}$ imidazole, $\mathrm{pH}$ 8.0). Cell disruption was performed using a Pressure Cell Homogeniser (SPCH-18) at $4{ }^{\circ} \mathrm{C}$. Cell lysate was centrifuged to remove the debris. Target proteins in supernatant were first purified via using nickelnitrilotriacetate (Ni-NTA) agarose, obtained proteins were then passed through the size exclusion column (Superdex 200; GE Healthcare, Shanghai, China) for further purification.

\subsection{Crystallization, Data Collection, and Structure Determination}

For crystallization screens, $10 \mathrm{mg} / \mathrm{mL}$ purified protein was incubated with thiosulfate at 1:20 molar ratio. Hampton Research kits and the hanging drop vapor diffusion method were used to get preliminary crystallization conditions. RDL2 crystal was obtained after one week incubation at $20^{\circ} \mathrm{C}$ in $3.5 \mathrm{M}$ ammonium citrate (pH 7.0). For data collection, crystals were flash-frozen in liquid nitrogen, with 15 20\% (v/v) ethylene glycol as cryoprotectant.

The X-ray diffraction data sets were collected at $100 \mathrm{~K}$ on a beam line BL17U at the Shanghai Synchrotron Radiation Facility (Shanghai, China) equipped with an ADSC Q315r CCD-detector. All data were processed using HKL-2000. The structure of RDL2-SSH was resolved by molecular replacement using Phaser from the CCP4 suit of programs, with RDL1 (PDB entry: 3D1P) as the search model. Refinement was performed using the PHENIX crystallography suite and the COOT interactive model-building program. The 
quality of final models was checked using the PROCHECK program. The structural figures were prepared with PyMOL.

\subsection{Protein LC-MS/MS Analysis}

The purified protein $(6.0 \mathrm{mg} / \mathrm{mL})$ was mixed with $200 \mu \mathrm{M}$ of thiosulfate in HEPES buffer $(100 \mathrm{mM}, \mathrm{pH} 7.4)$. After an incubation at $25^{\circ} \mathrm{C}$ for $20 \mathrm{~min}$, the mixture was loaded onto PD-10 desalting column to remove unreacted thiosulfate. The obtained protein sample was reacted with iodoacetamide (IAM) then digested with trypsin by following a previously reported protocol [30]. The Prominence nano-LC system (Shimadzu, Shanghai, China) equipped with a custom-made silica column $(75 \mu \mathrm{m} \times 15 \mathrm{~cm})$ packed with 3- $\mu \mathrm{m}$ Reprosil-Pur $120 \mathrm{C} 18-\mathrm{AQ}$ was used for the analysis. For the elution process, a $100 \mathrm{~min}$ gradient from $0 \%$ to $100 \%$ of solvent $\mathrm{B}(0.1 \%$ formic acid in $98 \%$ acetonitrile $)$ at $300 \mathrm{nl} / \mathrm{min}$ was used; solvent A was $0.1 \%$ formic acid in $2 \%$ acetonitrile). The eluent was ionized and electrosprayed via LTQ-Orbitrap Velos Pro CID mass spectrometer (Thermo Scientific, Shanghai, China) which was run in data-dependent acquisition mode with Xcalibur 2.2.0 software (Thermo Scientific). Full-scan MS spectra (from 400 to $1800 \mathrm{~m} / \mathrm{z}$ ) were detected in the Orbitrap with a resolution of 60,000 at $400 \mathrm{~m} / \mathrm{z}$.

\section{5. $R S_{2}$ Analysis of Thiosulfate and Proteins}

The RF-5301 PC Spectrofluoro Photometer (SHIMADZU) was used for $\mathrm{RS}_{2}$ analysis. Thiosulfate (12.5 mM) was diluted into $2 \mathrm{~mL}$ argon-deoxygenated buffers ( $\mathrm{pH} 3-10)$ in a parafilm-sealed fluorometer cell $(\mathrm{d}=1 \mathrm{~cm})$. After an incubation at $25^{\circ} \mathrm{C}$ for $30 \mathrm{~min}$. $\mathrm{RS}_{2}$ was acquired by simultaneously scanning the excitation $\left(\lambda_{e x}\right)$ and emission $\left(\lambda_{e m}\right)$ on monochromators setting the offset $\left(\Delta \lambda=\lambda_{e m}-\lambda_{e x}\right)$ to a constant as described previously [27]. All spectra were acquired with a scan rate of $60 \mathrm{~nm} / \mathrm{min}$. The measurement interval was $1.0 \mathrm{~nm}$ and the slit width was $5 \mathrm{~nm}$.

For protein analysis, the protein $(3.0 \mathrm{mg} / \mathrm{mL})$ was incubated with thiosulfate at 1:20 molar ratio in Tris- $\mathrm{HCl}$ buffer ( $50 \mathrm{mM}$, pH 7.4). After being incubated at $25^{\circ} \mathrm{C}$ for $20 \mathrm{~min}$, the mixture was loaded onto a PD-10 desalting column to remove small molecules. The obtained protein was diluted to $0.1 \mathrm{mg} / \mathrm{mL} \sim 0.5 \mathrm{mg} / \mathrm{mL}$ to let the $\mathrm{RS}_{2}$ signal intensity fall in the detection range of RF-5301 fluorometer. As the control, a protein sample without reacting with thiosulfate was also analyzed. $\Delta \mathrm{RS}_{2}$ at a specific wavelength was calculated by $\mathrm{RS}_{2}{ }^{w}$ reacted $-\mathrm{RS}_{2}{ }^{w}$ control (w is the wavelength). Total $\Delta \mathrm{RS}_{2}$ was calculated by adding up all $\Delta \mathrm{RS}_{2}$ values at the $240 \mathrm{~nm}-550 \mathrm{~nm}$ range.

\subsection{Thiosulfate:Cyanide Sulfurtransferase Activity Assay}

The activity on Reaction 1 was measured using a colorimetric assay method described previously [31]. The reaction mixture $(250 \mu \mathrm{L})$ contained $1 \mathrm{mM} 300 \mathrm{mM}$ thiosulfate, $1 \mathrm{mM} 300 \mathrm{mM}$ potassium cyanide, and $0.5 \mu \mathrm{g}$ rhodanese in $300 \mathrm{mM}$ HEPES, $\mathrm{pH}$ 7.4. The reaction was performed at room temperature for $5 \mathrm{~min}$ and was quenched by adding $250 \mu \mathrm{L}$ $15 \%(w / v)$ formaldehyde, followed by addition of $500 \mu \mathrm{L}$ ferric nitrate solution $(165 \mathrm{mM}$ ferric nitrate monahydrate, $13.3 \%(v / v)$ nitric acid). The absorbance of the resulting ferric thiocyanate complex was measured at $460 \mathrm{~nm}$. The concentration of thiocyanate was determined using a standard curve.

\subsection{Thiosulfate:GSH Sulfurtransferase Activity Assay}

The activity on Reaction 2 was measured by detecting $\mathrm{H}_{2} \mathrm{~S}$ formation using the lead acetate assay as described previously [32]. Briefly, the reaction mixture $(1 \mathrm{~mL})$ contained $0.1 \mathrm{mM} 20 \mathrm{mM}$ thiosulfate, $2 \mathrm{mM} \sim 40 \mathrm{mM} \mathrm{GSH}, 10 \mu \mathrm{g}$ of rhodanese, and $0.4 \mathrm{mM}$ leadacetate in $300 \mathrm{mM}$ HEPES buffer, $\mathrm{pH}$ 7.4. The reaction was performed at $37^{\circ} \mathrm{C}$ for $4 \mathrm{~min}$. Formation of lead sulfide was measured at $390 \mathrm{~nm}$. The concentration of $\mathrm{H}_{2} \mathrm{~S}$ formed was calculated using an extinction coefficient of $5500 \mathrm{M}^{-1} \mathrm{~cm}^{-1}$ for lead sulfide. 


\subsection{HPLC Analysis of the Products Generated by Thiosulfate Decomposition}

Thiosulfate $(500 \mathrm{mM})$ was diluted in buffers of different $\mathrm{pH}$ values and incubated at $25^{\circ} \mathrm{C}$ for $30 \mathrm{~min}$. The decomposition products were derivatized with methyl trifluoromethanesulfonate (methyl triflate) and analyzed by reversed-phase liquid chromatography using a C18 reverse phase column (VP-ODS, $150 \times 4 \mathrm{~mm}$, Shimadzu) and eluted with pure methanol. The peak positions of dimethylpolysulfides from $\mathrm{Me}_{2} \mathrm{~S}_{2}$ to $\mathrm{Me}_{2} \mathrm{~S}_{8}$ were identified using a protocol reported previously [33].

\subsection{Detection of Sulfane Sulfurs Using SSP4}

SSP4 (Sulfane Sulfur Probe 4) is a fluorescent probe to detect sulfane sulfurs specifically. SSP4 itself is non-fluorescent, but it emits strong green fluorescence after it reacts with sulfane sulfurs. Reactions of thiosulfate with SSP4 were conducted by mixing $10 \mu \mathrm{M} \mathrm{SSP} 4$ with $50 \mathrm{mM}, 100 \mathrm{mM}$, or $300 \mathrm{mM}$ thiosulfate in $200 \mu \mathrm{L}$ HEPES buffer (100 mM, pH 3.0). The mixture was incubated at room temperature for $30 \mathrm{~min}$, and then the fluorescence was detected by using the Synergy H1 microplate reader. The excitation wavelength was set to $482 \mathrm{~nm}$ and the emission wavelength was set to $515 \mathrm{~nm}$.

For analysis of thiosulfate decomposition, $1 \mathrm{M}$ thiosulfate was diluted into $200 \mu \mathrm{L}$ HEPES buffer (100 mM, pH 4.0) to a final concentration of $300 \mathrm{mM}$. $100 \mathrm{mM}$ Arg, Thr, or Gly was added individually. At the same time, $10 \mu \mathrm{M}$ of SSP4 was added to incubate with thiosulfate for $30 \mathrm{~min}$, and fluorescence was detected every $30 \mathrm{~s}$ by using the Synergy H1 microplate reader.

\subsection{Bioinformatics Analysis and Protein Structure Modeling}

The three-dimensional structure of TST was generated by SWISS-MODEL (http:/ / swissmodel.expasy.org/, accessed on 18 July 2018) using Bos taurus rhodanese (PDB entry: 1DP2) as the template ( $90.7 \%$ sequence similarity). The global QMEAN score was 0.70 for the TST model. The surface electrostatic potentials were analyzed by APBS-1.1.0, and the data and parameters were obtained with the PDB2PQR server (http:/ / nbcr-222.ucsd. edu/pdb2pqr_2.1.1/). The rhodanese pocket shape parameters were calculated using the Caver Analyst software (v2.0), whose binaries and documentation are freely available at http://www.caver.cz/.

\section{Results}

\subsection{Crystal Structure of RDL2}

The His-tag fused RDL2 was expressed in E. coli BL21(DE3) and purified using affinity chromatography. Its molecular weight is about $16.7 \mathrm{kDa}$ judged by SDS-PAGE analysis. The crystal structure of RDL2 co-crystallized with thiosulfate was obtained at $2.47 \AA$ resolution by molecular replacement using the RDL1 structure (PDB code: 3D1P) as template (Table 1). The final model contains two chains in the asymmetric unit (Figure 1A). Each molecule consists of a four-stranded parallel $\beta$-sheet core framed by six $\alpha$-helices, displaying as a typical $\alpha / \beta$ rhodanese domain. The intermolecular interactions between two chains involve in an interface of $432 \AA^{2}$, representing $6 \%$ of the total RDL2 surface. Only two hydrogen bonds are involved in the intermolecular interactions, suggesting that the interactions are mostly based on van der Waals contacts. This analysis indicates that RDL2 does not assemble as firm dimers during crystallization process.

Compared with RDL1 and TSTD1 that consist of five $\beta$-sheets and six $\alpha$-helices, RDL2 is lack of $\beta 1$ (Figure 1B). Structure alignment analysis demonstrates that Gln and Ser amino acid residues comprise $\beta 1$ in RDL1, whereas in RDL2, these positions are occupied by Lys and Ile amino acids, comprising an unspecific shape (Figure 1C). The catalytic Cys106 stretches out $\beta_{4}$ towards surface of RDL2. Electron density and bond length analysis indicates the presence of an extra sulfur atom $S_{\delta}$, forming a persulfide bond with the $S_{\gamma}$ atom of $\mathrm{Cys}_{106}$ (Figure 1D). The persulfide group of RDL2 is located in a peanut-like pocket of neutral electrostatic field. Adjacent to it is a cradle-like pocket with positive electrostatic field, which is attributed by $\operatorname{Arg}_{111}$ and $\operatorname{Arg}_{55}$ (Figure 1E). 
The active-site loop comprised by six sequential amino acids is the structural signature of rhodanese. In RDL2, the active-site loop is comprised by CAKGVR. The $\mathrm{NH}_{3}{ }^{+}$groups of $\operatorname{Arg}_{111}$ locate at $11.3 \AA$ away from the $\mathrm{S}_{\delta}$ atom, and $\mathrm{NH}_{3}{ }^{+}$group of Lys 108 locates further, suggesting that they cannot form hydrogen bond with the $S_{\delta}$ atom of $C_{106}$. Other neighbour residues including $\mathrm{Ile}_{129}, \mathrm{Pro}_{131}$, and $\mathrm{Tyr}_{130}$ also locate at distances beyond a hydrogen bond (Figure $1 F$ ). This analysis indicates that the persulfide group of Cys 106 is not stabilized by specific residue(s) in RDL2.

Table 1. X-ray data collection and refinement statistics.

\begin{tabular}{cc}
\hline Data Collection & \\
\hline Space group & $I 4_{1}$ \\
Cell dimensions & \\
$a, b, c(\AA)$ & $79.753,79.753,110.382$ \\
$\alpha, \beta, \gamma\left({ }^{\circ}\right)$ & $90.00,90.00,90.00$ \\
Wavelength $(\AA)$ & 0.9791 \\
Resolution $(\AA)$ & $50.00-2.47(2.51-2.47)$ \\
$\langle I / \sigma(I)\rangle$ & $24.69(3)$ \\
Completeness $(\%)$ & $100.0(99.7)$ \\
Redundancy & $13.1(10.3)$ \\
CC $1 / 2$ & $0.990(0.976)$ \\
$R_{\text {pim }}$ & $0.028(0.230)$ \\
Refinement & \\
Resolution $(\AA)$ & $27.595-2.471$ \\
No. reflections & 11,448 \\
$R_{\text {work }} / R_{\text {free }}(\%)$ & $20.77 / 24.72$ \\
No. atoms & \\
Protein & 1952 \\
Water & 57 \\
B-factors & \\
Protein & 35.37 \\
Water & 32.55 \\
RMS deviations & \\
Bond lengths $(\AA)$ & 0.002 \\
Bond angles $\left({ }^{\circ}\right)$ & 0.516 \\
Ramachandran Plot & \\
favored & $99.15 \%$ \\
allowed & $0.85 \%$ \\
outliers & $0.00 \%$ \\
\hline
\end{tabular}

\subsection{Tandem MS Analysis of Thiosulfate Reacted-RDL2}

We also analyzed the thiosulfate-reacted RDL2 (without a sulfur acceptor) by using LCMS/MS. A peptide containing $\mathrm{Cys}_{106}$ was detected with a molecular weight of 2320.19 Da, corresponding to the $\mathrm{Cys}_{106}-\mathrm{SSH}$ modification (Figure S1). This modification was not detected in DTT treated RDL2. This analysis confirmed that a sulfur atom is transferred from thiosulfate to RDL2 to form the $E S^{0}$ intermediate.

\subsection{Activity Assay of RDL2}

RDL2 shows typical sulfurtransferase activity evidenced by efficiently catalyzing the Reaction 1. The $K_{m}$ values for thiosulfate and cyanide are $32.50 \pm 3.50 \mathrm{mM}$ and $5.85 \pm 2.18 \mathrm{mM}$, respectively, the $V_{\text {max }}$ is $55.04 \pm 3.27 \mu \mathrm{mol} \mathrm{min}{ }^{-1} \mathrm{mg}^{-1}$ and the $k_{\text {cat }}$ is $15.32 \mathrm{~s}^{-1}$ at $25^{\circ} \mathrm{C}$. It also catalyzes the Reaction 2 and the $K_{m}$ values for thiosulfate and GSH are $2.54 \pm 0.27 \mathrm{mM}$ and $50.01 \pm 8.73 \mathrm{mM}$, respectively, the $V_{\text {max }}$ is $0.357 \pm 0.031 \mu \mathrm{mol} \mathrm{min}{ }^{-1} \mathrm{mg}^{-1}$ and the $k_{\text {cat }}$ is $0.099 \mathrm{~s}^{-1}$ at $25{ }^{\circ} \mathrm{C}$ (Figure 2 and Table 2). RDL1 and RDL2 are both sulfotransferases in Saccharomyces cerevisiae with similar structures. We also analyzed RDL1 activity. For Reaction 1, The $K_{m}$ values for thiosulfate and cyanide were $4.0 \pm 0.4 \mathrm{mM}$ and $2.6 \pm 0.3 \mathrm{mM}$. For Reaction 2, the Km values for thiosulfate and GSH were $3.1 \pm 0.3 \mathrm{mM}$ and $5.6 \pm 0.8 \mathrm{mM}$. These results indicate that as RDL2, RDL1 also has the sulfane sulfur transferring activity. 

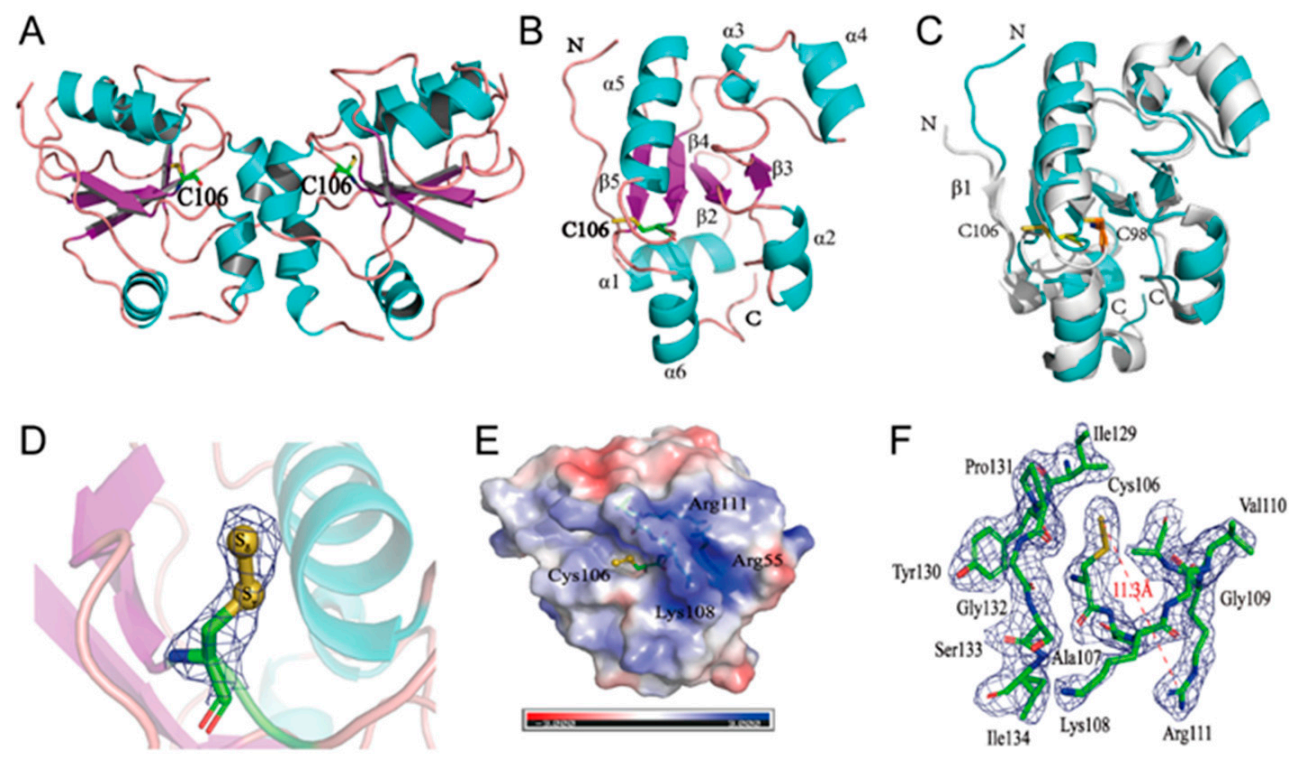

Figure 1. Crystal structure of RDL2 (S. cerevisiae rhodanese 2). (A) The X-ray crystal structure of RDL2 was solved at $2.47 \AA$ by molecular replacement using the RDL1 structure (PDB entry: 3D1P) as a template. The structure of RDL2 has two asymmetric chains. (B) The monomer of RDL2 consists of a four-stranded parallel $\beta$-sheet core (purple) surrounded by six $\alpha$-helices (blue). Cys 106 is shown in stick representation. (C) Alignment of RDL2 structure (blue) with RDL1 (S. cerevisiae rhodanese 1) structure (white). (D) The electron density map of active site cysteine. The persulfide bond is formed by the $S_{\gamma}$ atom of $\mathrm{Cys}_{106}$ with a $\mathrm{S}_{\delta}$ atom. The electron density map (2Fo-Fc) is contoured at $1.5 \sigma$. (E) The surface electrostatic potential representation of RDL2. Cys 106 is located in a peanut-like pocket of neutral electrostatic field. $\mathrm{Arg}_{111}, \mathrm{Arg}_{55}$ and $\mathrm{Lys}_{108}$ in the vicinity of the persulfide group form a positive electrostatic field. Positive and negative electrostatic potentials are shown in blue and red, respectively in the range of $\pm 3 \mathrm{kT} / \mathrm{e}$. $(\mathbf{F})$ The distance between $\mathrm{NH}_{3}{ }^{+}$group of $\mathrm{Arg}_{111}$ and $\mathrm{S}_{\delta}$ atom of $\mathrm{Cys}_{106}$ is shown in red line. The distances between $S_{\delta}$ atom and neighboring residues all exceed the hydrogen bond range.

A

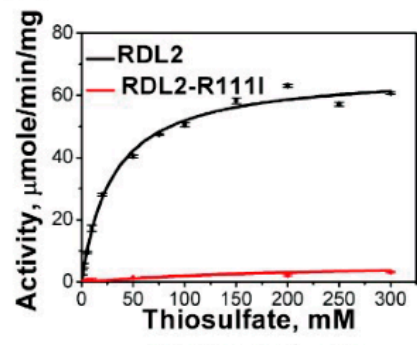

B

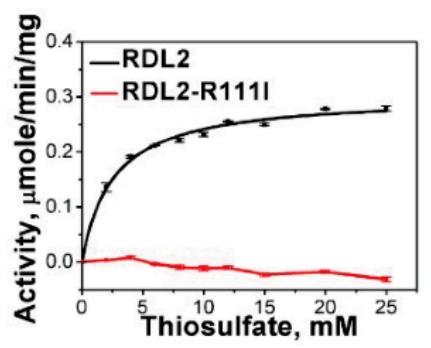

Reaction1
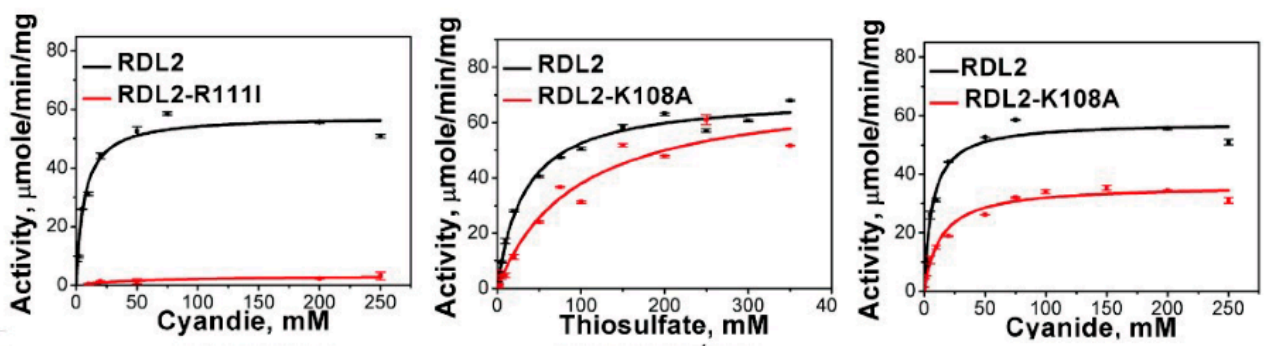

\section{Reaction2}

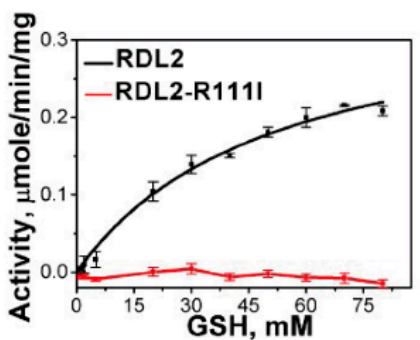

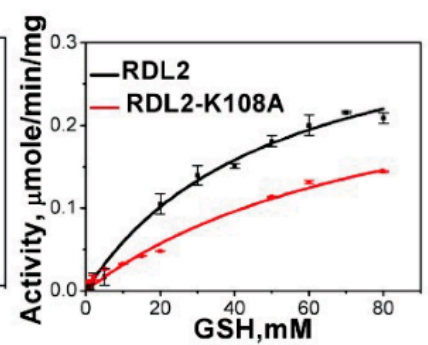

Figure 2. Kinetics of RDL2-catalyzed Reactions 1 (A) and 2 (B). The data shown as average \pm s.d. are all from 3 independent experiments and fitted with Michaelis-Menten equation. 
Table 2. Kinetic parameters of RDL2-catalyzed Reactions 1 and 2.

\begin{tabular}{|c|c|c|c|c|c|c|c|}
\hline & Rhodanese & $K_{m}$ Donor mM & $K_{m}$ Acc. $\mathbf{m M}$ & $\begin{array}{c}V_{\max } \\
\mu \mathrm{mol} \min ^{-1} \mathrm{mg}^{-1}\end{array}$ & $k_{\text {cat }} \mathbf{s}^{-1}$ & $\begin{array}{c}k_{c a t} / K_{m} \text { Donor } \\
\mathbf{M}^{-1} \mathbf{s}^{-1}\end{array}$ & $\begin{array}{c}K_{c a t} / K_{m} \text { Acc. } \\
\mathbf{M}^{-1} \mathbf{s}^{-1}\end{array}$ \\
\hline \multirow{3}{*}{ Reaction 1} & RDL2 & $32.5 \pm 3.50$ & $5.85 \pm 2.18$ & $55.04 \pm 3.27$ & 15.32 & $0.47 \times 10^{3}$ & $2.62 \times 10^{3}$ \\
\hline & RDL2-R111I & $100.66 \pm 55.95$ & $60.12 \pm 33.78$ & $3.40 \pm 0.61$ & 0.95 & 9.43 & 15.8 \\
\hline & RDL2-K108A & $93.23 \pm 2.67$ & $9.13 \pm 3.78$ & $31.31 \pm 2.21$ & 8.71 & 93.42 & $0.95 \times 10^{3}$ \\
\hline \multirow{3}{*}{ Reaction 2} & RDL2 & $2.54 \pm 0.27$ & $50.01 \pm 8.73$ & $0.357 \pm 0.031$ & 0.099 & 38.98 & 1.98 \\
\hline & RDL2-R111I & - & - & - & - & - & - \\
\hline & RDL2-K108A & $4.79 \pm 0.57$ & $69.41 \pm 13.51$ & $0.153 \pm 0.016$ & 0.042 & 8.77 & 0.61 \\
\hline
\end{tabular}

Note: For reaction $1, K_{m}$ Donor is assayed using fixed $\mathrm{KCN}$ concentration and different thiosulfate concentrations. $K_{m}$ Acc is assayed using fixed thiosulfate concentration and different $\mathrm{KCN}$ concentrations. For reaction $2, K_{m}$ Donor is assayed using fixed GSH concentration and different thiosulfate concentrations. $K_{m}$ Acc is assayed using fixed thiosulfate concentration and different GSH concentrations. Data shown as average \pm s.d. are all from 3 independent experiments. The mutations that losing activity $(-)$ is confirmed with two independent experiments.

\subsection{Effect of Arg $_{111}$ on RDL2 Activity}

We suspected that $\operatorname{Arg}_{111}$ may participate in thiosulfate anion $\left(\mathrm{S}_{2} \mathrm{O}_{3}{ }^{2-}\right)$ or cyanide anion $\left(\mathrm{CN}^{-}\right)$trapping. To test this, we mutated $\mathrm{Arg}_{111}$ to Ile. The R111I mutant lost about $90 \%$ activity of catalysing Reaction 1 . The $K_{m}$ values for thiosulfate and cyanide increase to $100.66 \pm 55.95 \mathrm{mM}$ and $60.12 \pm 33.78 \mathrm{mM}$, respectively, indicating that the affinity for both of them is severely impaired. No activity on Reaction 2 was detected (Figure 2 and Table 2).

We recently reported a resonance synchronous spectroscopy $\left(\mathrm{RS}_{2}\right)$ method for detecting both sulfane sulfur containing compounds and $E S^{0}$ intermediate of rhodanese. They show strong $\mathrm{RS}_{2}$ signal in $\mathrm{Uv}$-Vis range due to the presence of active sulfane sulfur. Thiosulfate has no significant $\mathrm{RS}_{2}$ signal at $\mathrm{pH} 4 \sim 10$ range [27]. Compared to reduced rhodanese (Cys-SH), $E S^{0}$ intermediate (rhodanese-SSH) has significant higher $\mathrm{RS}_{2}$ signal. Therefore, by detecting the change of $\mathrm{RS}_{2}$ signal, we can infer whether the rhodanese contains Cys-SSH. $\triangle \mathrm{RS}_{2}$ reflects the change of $\mathrm{RS}_{2}$ signal, which is calculated by $\Delta \mathrm{RS}_{2}=\mathrm{RS}_{2}$ reacted-rhodanese $-\mathrm{RS}_{2}$ reduced rhodanese. Total $\Delta \mathrm{RS}_{2}$ was calculated by adding up all $\Delta \mathrm{RS}_{2}$ values at $240 \mathrm{~nm} \sim 550 \mathrm{~nm}$ range. If total $\Delta \mathrm{RS}_{2}$ is a positive value, the reacted rhodanese should contain Cys-SSH. If total $\Delta \mathrm{RS}_{2}$ is a lower or zero value, the reacted rhodanese should contain less or no Cys-SSH. Herein, we used this method to detect the thiosulfate-reacted RDL2. RDL2 wild type (wt) has obviously increased $\mathrm{RS}_{2}$ signal after reacting with thiosulfate. The total $\Delta \mathrm{RS}_{2}$ value, which represents the $\mathrm{RS}_{2}$ increase degree, is 23,648.83 RI ( $\mathrm{RS}_{2}$ Intensity) (Figure 3 and Figure S2), indicating the formation of RDL2-SSH intermediate on Cys ${ }_{106}$. This observation is consistent with the result of LC-MS/MS analysis. Whereas, R111I has no increased $\mathrm{RS}_{2}$ signal after reacting with thiosulfate (Figure 3 and Figure S2), indicating that no sulfur atom is transferred to the Cys ${ }_{106}$ residue of R111I. These results indicate that $\mathrm{Arg}_{111}$ is involved in thiosulfate trapping and sulfur transferring from thiosulfate to Cys 106 .

\subsection{Effect of Lys 108 on RDL2 Activity}

The RDL2 active-site loop contains another basic amino acid residue Lys 108 . Its location is not in the cradle- or peanut-like pocket, suggesting a nonessential role for RDL2 activity. To test this, we mutated it to Ala. The K108A mutant showed partially decreased activity of catalyzing Reactions 1 and 2, evidenced by the higher $K_{m}$ values, and lower $V_{\max }$ and $k_{\text {cat }}$ values than that of RDL2 wt (Figure 2 and Table 2). The thiosulfate-reacted K108A mutant shows increased $\mathrm{RS}_{2}$ signal (total $\Delta \mathrm{RS}_{2}=8562.64 \mathrm{RI}$ ) but the increasing amplitude is obviously lower than that of RDL2 wt enzyme (total $\Delta \mathrm{RS}_{2}=23,648.83 \mathrm{RI}$ ) (Figure 3 and Figure S2). These results indicated that although not as efficient as RDL2 wt, K108A still can form $\mathrm{Cys}_{106}$-SSH intermediate after reacting with thiosulfate, and still can transfer the sulfane sulfur from $\mathrm{Cys}_{106}-\mathrm{SSH}$ to $\mathrm{CN}^{-}$or GSH. Hence, in consistent with its peripheral location, Lys $_{108}$ is not essential for the rhodanese activity. 
A

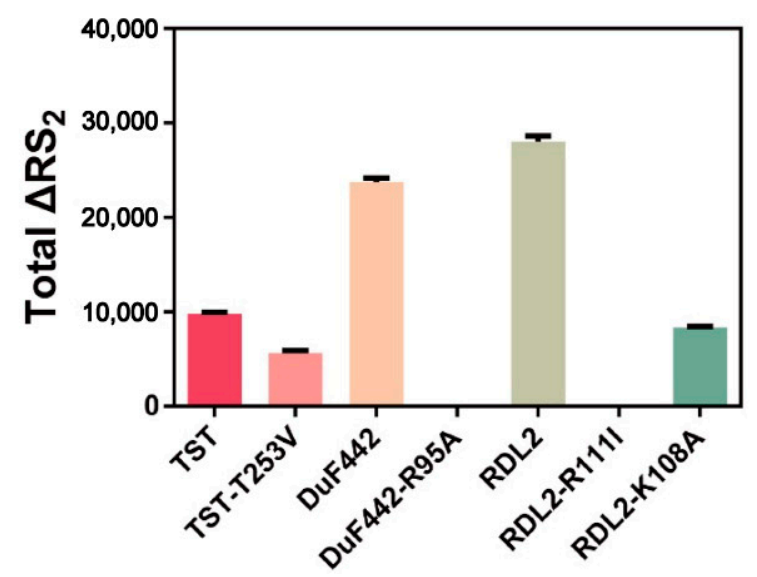

B

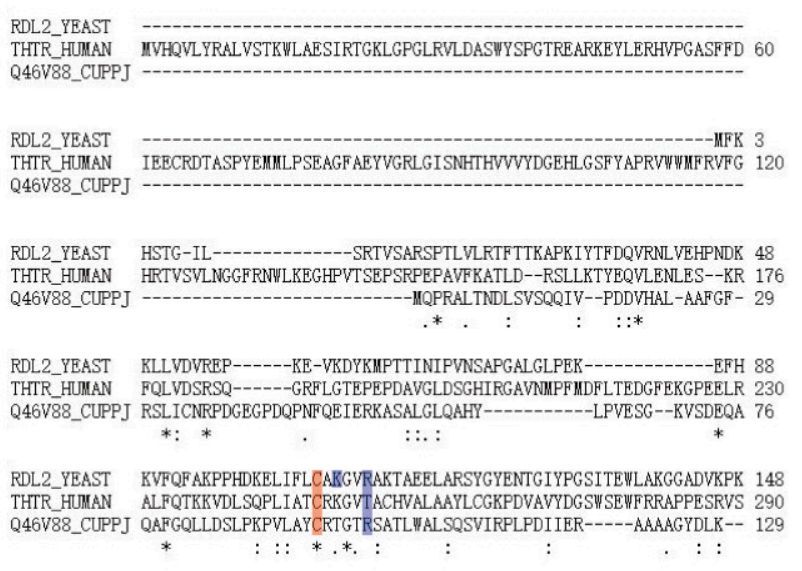

Figure 3. Total $\Delta \mathrm{RS}_{2}$ values of enzymes and their mutants. (A) After reacting with thiosulfate, TST, DUF442, and RDL2 show positive total $\triangle \mathrm{RS}_{2}$ values, indicating they form Cys-SSH intermediates; TST-T253V and RDL2-K108A mutants show decreased total $\Delta \mathrm{RS}_{2}$ values compared to wt, indicating they contain less Cys-SSH than corresponding wt; DUF442-R95A and RDL2-R111I show zero $\Delta \mathrm{RS}_{2}$ values, indicating they contain no Cys-SSH. (B) Sequence alignment of the rhodaneses. The conserved cysteine residue and mutation sites are shaded in color. * indicates the conserved residue.

\subsection{Effects of Arg $_{99}$ on DUF442 Activity}

Recently, we identified a rhodanese-like domain (DUF442) from the sulfide: quinone oxidoreductase of C. pinatubonensis JMP134 which can catalyze sulfane sulfur transfer reactions and whose active-site loop is comprised by CRTGTR [11]. Homology modeling analysis indicated that like $\mathrm{Arg}_{111}$ in RDL2, the loop-end $\mathrm{Arg}_{99}$ also contributes to the positive electrostatic field in DUF442. To see whether $\mathrm{Arg}_{99}$ is involved in thiosulfate trapping like Arg 111 of RDL2, we constructed a R99I mutant. DUF442-R99I lost about 95\% activity when catalyzing Reaction 1 (Figure 4 and Table 3). The $K_{m}$ value for thiosulfate ( $K_{m}$ Donor) increases to $227.68 \pm 95.64 \mathrm{mM}$, about 150-fold higher than that of DUF442 wt $(1.61 \pm 0.45 \mathrm{mM})$, other characteristics including $K_{m}$ value for $\mathrm{KCN}\left(K_{m} \mathrm{Acc}\right), V_{\max }$, and $k_{c a t}$ are also impaired. For Reaction 2, no activity was detected from the R99I mutant while wt showed apparent activity. These results indicate that $\mathrm{Arg}_{99}$ is critical for DUF442 activity.

We also used $\mathrm{RS}_{2}$ method to analyze DUF442 wt and the R99I mutant. DUF4422 wt showed obviously increased $\mathrm{RS}_{2}$ signals after reacting with thiosulfate. The total $\Delta \mathrm{RS}_{2}$ value is 23,588.28 RI. Whereas, R99I showed no $\mathrm{RS}_{2}$ increase after reaction (Figure 3 and Figure S2). These results indicated that like $\mathrm{Arg}_{111}$ for RDL2, $\mathrm{Arg}_{99}$ is also involved in the process of transferring a sulfur from thiosulfate to Cys 94 .

\subsection{Effect of the Loop-End Thr 253 on TST Activity}

TST is a tandem-domain type rhodanese locating in mitochondrion of human cell (GenBank No. NP_001257412.1). Homology modelling analysis indicated that only the second domain contains an active-site loop CRKGVT. As the position of loop-end Arg in RDL2 or DUF442, the loop-end Thr also locates in the pocket with positive electrostatic field according to the modelled structure (Figure S3). To test whether it functions similarly as the former two amino acids we mutated it to Val. The T253V mutant totally loses the activity of catalyzing Reaction 1 while TST wt shows apparent activity (Figure 4 and Table 3). Interestingly, its activity of catalyzing Reaction 2 is not significantly changed compared with that of TST wt, probably because the activity on Reaction 2 is already very low, evidenced by the low $V_{\text {max }}\left(0.04 \sim 0.10 \mu \mathrm{mol} \mathrm{min}^{-1} \mathrm{mg}^{-1}\right)$ and $k_{\text {cat }}$ values $\left(0.02 \sim 0.06 \mathrm{~s}^{-1}\right)$. We also noticed that TST wt has much higher activity toward reaction 1 than 2, evidenced by the much higher $V_{\max }(176.9$ vs. 0.09$)$ and $k_{\text {cat }}$ values (101.7 vs. 0.055$)$. Nonetheless, these results indicate that $\mathrm{Thr}_{253}$ is important for TST activity. 
The $\mathrm{RS}_{2}$ analysis demonstrated that thiosulfate-reacted TST has obviously increased $\mathrm{RS}_{2}$ signal (total $\Delta \mathrm{RS}_{2}=9960.69 \mathrm{RI}$ ) while T253V has slightly increased (total $\Delta \mathrm{RS}_{2}=7076.96 \mathrm{RI}$ ) after reacting with thiosulfate (Figure 3 and Figure S2), indicating that sulfur transferring process is impaired by the $\mathrm{T} 253 \mathrm{~V}$ mutation.

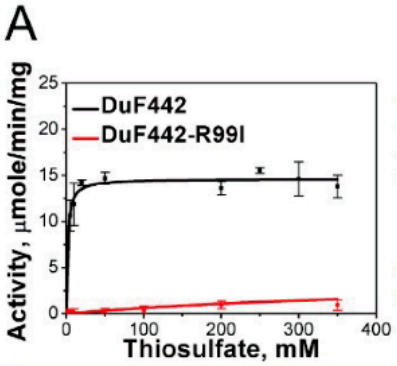

B

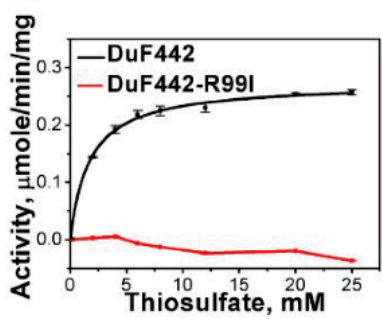

Reaction1
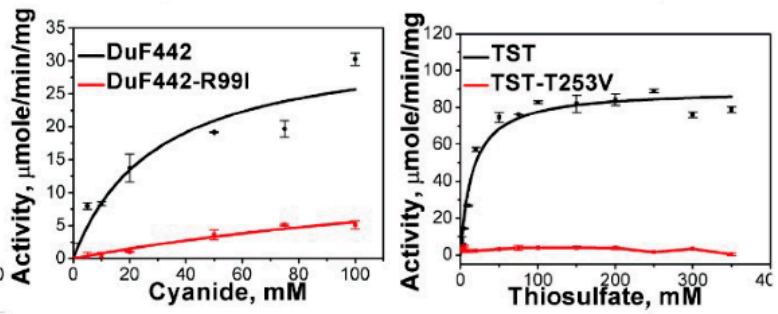

\section{Reaction2}
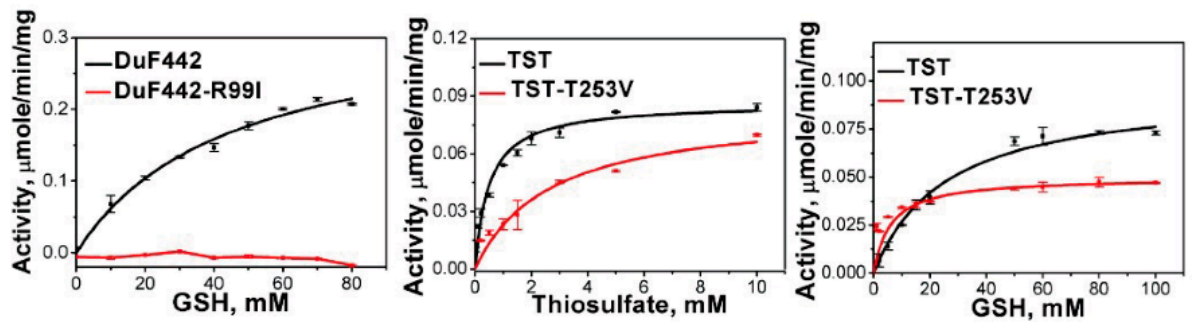

Figure 4. Kinetics of DUF442 and TST-catalyzed Reactions 1 (A) and 2 (B). The data shown as average \pm s.d. are all from 3 independent experiments and fitted with Michaelis-Menten equation.

Table 3. Kinetic parameters of DUF442 and TST.

\begin{tabular}{|c|c|c|c|c|c|c|c|}
\hline & Rhodanese & $K_{m}$ Donor mM & $K_{m}$ Acc. $\mathbf{m M}$ & $\begin{array}{c}V_{\max } \\
\mu \mathrm{mol} \min -1 \mathrm{mg}-1\end{array}$ & $k_{c a t} s-1$ & $\begin{array}{c}k_{c a t} / K_{m} \text { Donor } \\
\mathrm{M}-1 \mathrm{~s}-1\end{array}$ & $\begin{array}{c}K_{c a t} / K_{m} \text { Acc. } \\
\mathbf{M}-1 \mathrm{~s}-1\end{array}$ \\
\hline \multirow{4}{*}{ Reaction 1} & DUF442 & $1.61 \pm 0.45$ & $13.27 \pm 0.91$ & $21.18 \pm 0.86$ & 4.89 & $3.04 \times 103$ & $0.37 \times 103$ \\
\hline & DUF442-R99I & $227.68 \pm 95.64$ & $132.2 \pm 28.42$ & $8.12 \pm 0.76$ & 1.88 & 6.77 & 14.22 \\
\hline & TST & $15.68 \pm 2.86$ & $26.59 \pm 2.34$ & $176.90 \pm 3.39$ & 101.73 & $6.49 \times 103$ & $3.83 \times 103$ \\
\hline & TST-T253V & - & - & - & - & - & - \\
\hline \multirow{4}{*}{ Reaction 2} & DUF442 & $1.53 \pm 0.35$ & $44.7 \pm 7.41$ & $0.334 \pm 0.026$ & 0.078 & 50.98 & 1.74 \\
\hline & DUF442-R99I & - & - & - & - & - & - \\
\hline & TST & $0.49 \pm 0.10$ & $25.62 \pm 3.94$ & $0.096 \pm 0.005$ & 0.055 & $0.11 \times 103$ & 2.15 \\
\hline & TST-TV & $2.43 \pm 0.70$ & $1.77 \pm 0.53$ & $0.044 \pm 0.002$ & 0.025 & 10.29 & 14.12 \\
\hline
\end{tabular}

Note: For reaction $1, K_{m}$ Donor is assayed using fixed $\mathrm{KCN}$ concentration and different thiosulfate concentrations. $K_{m}$ Acc is assayed using fixed thiosulfate concentration and different KCN concentrations. For reaction 2, $K_{m}$ Donor is assayed using fixed GSH concentration and different thiosulfate concentrations. $K_{m}$ Acc is assayed using fixed thiosulfate concentration and different GSH concentrations. Data shown as average \pm s.d. are all from 3 independent experiments. The mutations that losing activity $(-)$ is confirmed with two independent experiments.

\subsection{Analysis of Active-Site Loops and Positive Electrostatic Fielding-Pockets of Structured Rhodaneses}

Seeing the critical role of loop-end amino acids for rhodaneses, we analyzed all rhodanese structures that have been deposited in the PDB database (until 10 April 2021, sulfurtransferases catalyzing methionine or cystine decomposition were not included). In total, 13 structures were downloaded and categorized into different groups based on the loop-end amino acids. We found that eight of the rhodaneses contained Arg at the end of active-site loops, three contained Thr and two contained Ser (Table 4). 
Table 4. Structured rhodaneses downloaded from the PDB database.

\begin{tabular}{ccccc}
\hline Cluster & Name & Organism & PDB ID & Loop Sequence \\
\hline \multirow{2}{*}{ Arg } & TSTD1 & Homo sapiens & 6BEV & CQMGKR \\
& RDL1 & Saccharomyces cerevisiae & 3D1p & CASGKR \\
& YgaP & Escherichia coli & 5HPA & CQAGKR \\
& YnjE & Escherichia coli & 2WLR & CGTGWR \\
& SACOL1807 & Staphylococcus aureus & 3IWH & CAGGVR \\
& Bphyt_4191 & Paraburkholderia phytofirmans & 5VE3 & CRAGGR \\
& Rv0390 & Mycobacterium tuberculosis & 2FSX & CRSGNR \\
& TVG0868615 & Thermoplasma volcanium & 3GK5 & CAHGNR \\
Thr & MST & Homo sapiens & 4JGT & CGSGVT \\
& MST & Leishmania major & 1OKG & CGSGVT \\
& TST & Bos taurus & 1BOH & CRKGVT \\
Ser & GlpE & Escherichia coli & 1GMX & CYHGNS \\
& TUM1 & Saccharomyces cerevisiae & 3UTN & CGTGVS \\
\hline
\end{tabular}

We observed a common feature among 13 structured rhodaneses. Their loop-end amino acids all locate in superficial pockets with positive electrostatic fields, suggesting involvement of these pockets in thiosulfate trapping or binding. To see whether these pockets have shape similarities. We measured the radius, length, and curvature parameters of these pockets and performed statistical analysis on obtained data. However, results showed that the pockets have significant variances in these parameters, especially in length and curvature (Figure 5) suggesting no obvious shape similarities among them.
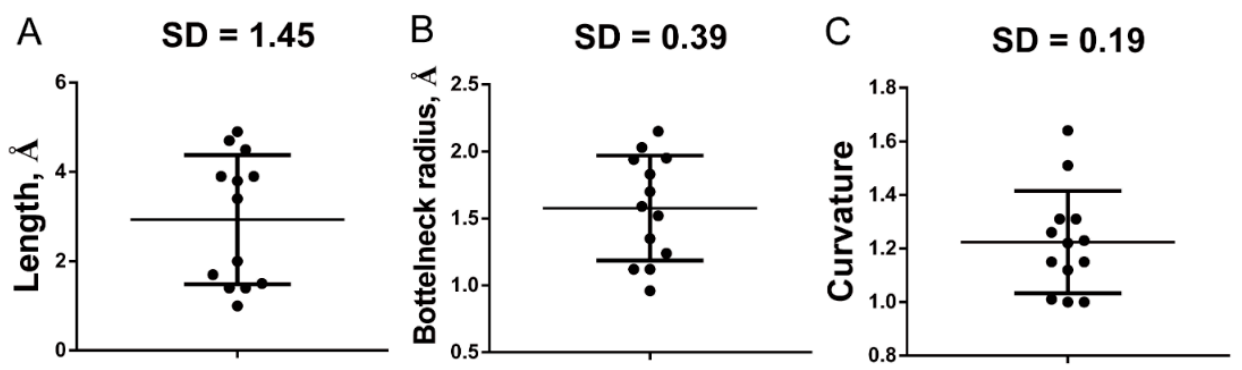

Figure 5. Shape parameters of the catalyzing pockets of structured rhodaneses. The rhodanese structures were downloaded from PDB database (Table S1). The length (A), bottleneck radius (B) and curvature (C) parameters of their catalyzing pockets were calculated using the Caver Analysis software (v2).

\subsection{Effects of Arg and Thr on Acidic Decomposition of Thiosulfate}

It has been reported that thiosulfate is unstable in acidic solutions due to decomposition to sulfane sulfur and sulfite [6]. We used $\mathrm{RS}_{2}$ to study the $\mathrm{pH}$ effects on thiosulfate decomposition. When $12.5 \mathrm{mM}$ thiosulfate was dissolved in $\mathrm{pH} 4.0 \sim 10.0$ solutions at $25^{\circ} \mathrm{C}$, no $\mathrm{RS}_{2}$ signal was detected. Whereas, when $\mathrm{pH} \leq 3.0$ solution was used, significant $\mathrm{RS}_{2}$ signal was observed (Figure 6A), indicating the generation of sulfane sulfur containing products. HPLC analysis indicated that $\mathrm{S}_{8}$, the aggregated form of sulfane sulfur, is generated at $\mathrm{pH}$ 3.0, but not in $\mathrm{pH} 10.0$ condition from thiosulfate decomposition (Figure S4). We also used a fluorescence based per/polysulfides detection probe SSP4 to react with decomposed thiosulfate (at pH 3.0) and observed significant fluorescent signals (Figure 6B). Together, these results validated the decomposition of thiosulfate in acidic condition.

Given the wide presence of Arg and Thr in rhodaneses active-site loops, we wondered whether they could affect thiosulfate decomposition. We added Arg into thiosulfate solution ( $\mathrm{pH}=4)$ and using SSP4 probe to detect the decomposition. Results indicated that the decomposition is obviously accelerated compared to that without Arg addition. The addition of Thr led to similar effects. As the control, Gly had no such effect (Figure 6C). 
These results indicated that the side chain groups of Arg and $\mathrm{Thr}, \mathrm{NH}_{3}{ }^{+}$and $\mathrm{OH}$, are responsible for the decomposition enhancement.
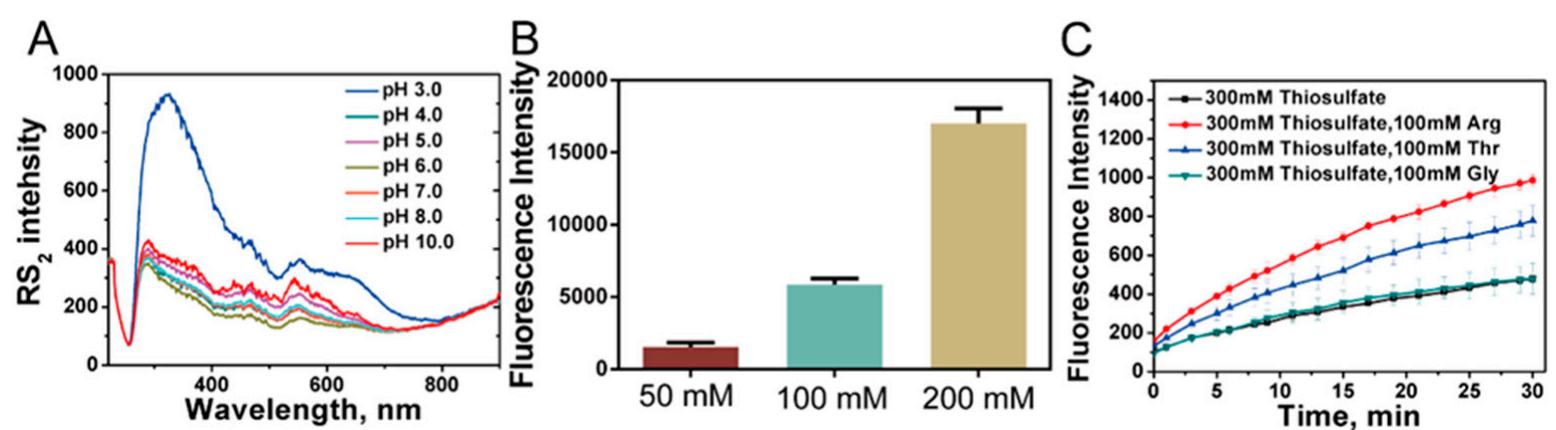

Figure 6. The effects of Arg and Thr on spontaneous decomposition of thiosulfate. (A) Thiosulfate was dissolved in $\mathrm{pH}$ buffers of different $\mathrm{pH}(3.0-10.0)$. $\mathrm{RS}_{2}$ was measured after a $30 \mathrm{~min}$ incubation at $25^{\circ} \mathrm{C}$. (B) Thiosulfate was reacted with SSP4 at pH 3.0 condition. (C) Thiosulfate was reacted with SSP4 at pH 4.0 condition, with or without presence of Arg, Thr or Gly.

\subsection{A Proposed Model for Rhodaneses Catalyzed Thiosulfate Decomposition}

The 3D structure data indicate that Arg/Thr are spatially near to the conserved cysteine. Activity assay experiments indicate that they are critical for catalyzing the sulfane sulfur transfer. In vitro chemical reactions indicate they can propel thiosulfate decomposition. These results form an evidence chain and, based on this chain, we proposed a model for explaining how sulfane sulfur is transferred from stable thiosulfate to unstable $E S^{0}$ at physiological $\mathrm{pH}$ (Figure 7). First, $\mathrm{S}_{2} \mathrm{O}_{3}{ }^{2-}$ is attracted by and trapped in the positive electrostatic-fielding pocket that locates on the surface of rhodaneses. Second, $\mathrm{NH}_{3}{ }^{+}$group of Arg or $\mathrm{OH}$ group of Thr/Ser can donate shared hydrogen bond(s) to $\mathrm{S}_{2} \mathrm{O}_{3}{ }^{2-}$, which makes $\mathrm{S}_{2} \mathrm{O}_{3}{ }^{2-}$ exist as $\mathrm{H}_{2} \mathrm{~S}_{2} \mathrm{O}_{3}$ or $\mathrm{HS}_{2} \mathrm{O}_{3}{ }^{-}$form in the pocket, and hence leads to decomposition of the latter two. Third, the released sulfane sulfur from the decomposition reaction is attached to the Cys-SH group of the active-site to form Cys-SSH, and consequently the $E S^{0}$ forms.

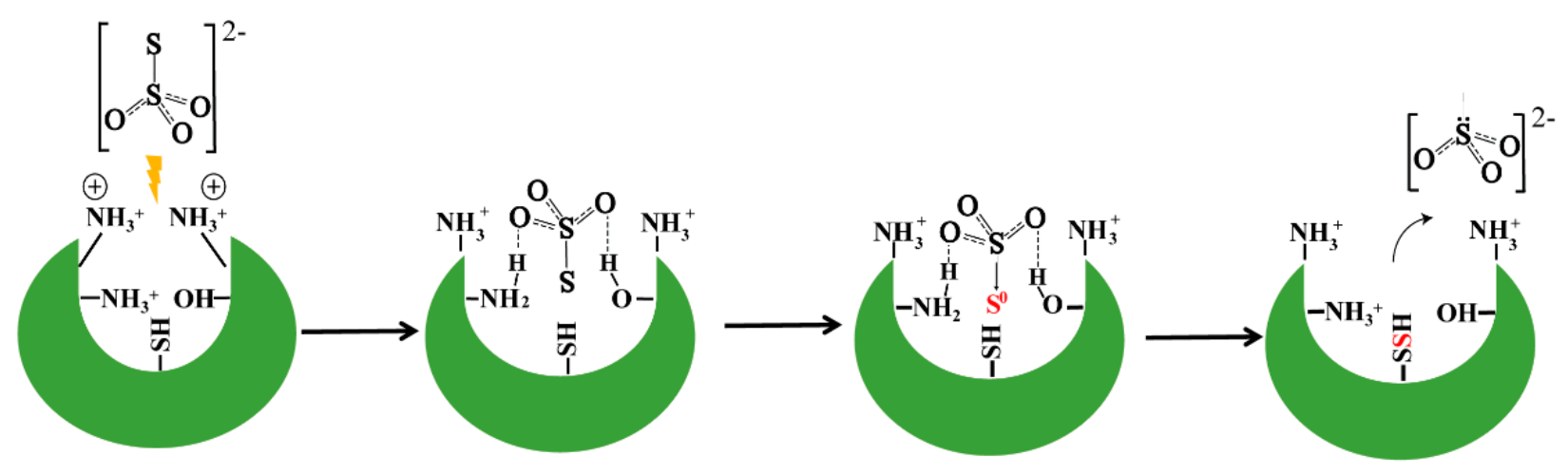

Figure 7. A proposed mechanism for sulfane sulfur transfer from thiosulfate to rhodanese.

\section{Discussion}

A pocket with positive electrostatic field near or surrounding the catalysis Cys is found in all reported rhodanese structures. This positive electrostatic field is attributed to basic or hydroxyl amino acids. It has been hypothesized that these amino acid residues participate in binding thiosulfate in the correct orientation to make its S-S bond close to the Cys thiol. After the sulfane sulfur transfer, these amino acid residues can stabilize the Cys-SSH and allow approach of the sulfur acceptor [21,26]. In this study, we obtained crystal structure of RDL2-SSH, the $E S^{0}$ state of $S$. cerevisiae mitochondrial rhodanese. The persulfide group is not located in the pocket of the positive electrostatic field, and its 
$\mathrm{S}_{\delta}$ atom is far away from the amide groups of $\mathrm{Arg}_{111}$ or Lys 108 . The location does not support the hypothesis that $\mathrm{Arg}_{111}$ can stabilize $\mathrm{Cys}_{106}-\mathrm{SSH}$. We also performed a survey on structured rhodaneses and found that the amino acid composition of their active-site loops and the shapes of positive-electrostatic-fielding pockets have unneglectable variances. Therefore, the proposal that basic amino acids can orientate thiosulfate to a specific position in the pocket is also questionable.

Chemical analysis indicated that thiosulfate is prone to decompose in $\mathrm{pH} \leq 3$ conditions due to the formation of $\mathrm{H}_{2} \mathrm{~S}_{2} \mathrm{O}_{3}$ or $\mathrm{HS}_{2} \mathrm{O}_{3}{ }^{-}$. Its decomposition leads to the production of sulfane sulfurs and sulfite. We observed that Arg and Thr can accelerate the decomposition reaction, most probably because they can offer shared $\mathrm{H}$-hydrogen bonds to neutralize $\mathrm{O}^{-}$anions, propelling the formation of $\mathrm{H}_{2} \mathrm{~S}_{2} \mathrm{O}_{3}$ or $\mathrm{HS}_{2} \mathrm{O}_{3}{ }^{-}$. Combined with the finding that Arg and Thr/Ser are prevalent loop-ending amino acids in rhodaneses, we propose that Arg or Thr/Ser in the catalysis pocket does not orientate thiosulfate to near the Cys thiol but offer a microenvironment to allow the formation of $\mathrm{H}_{2} \mathrm{~S}_{2} \mathrm{O}_{3}$ or $\mathrm{HS}_{2} \mathrm{O}_{3}{ }^{-}$, which spontaneously decomposes. It is noteworthy that the catalysis Cys thiol may also contribute to the microenvironment. We mutated the $\mathrm{Cys}_{106}$ of RDL2 to Ser 106 and found that this mutant lost the catalysis activity on both Reactions 1 and 2. The Cys mutation in DUF442 led to the same result (data not shown), suggesting Cys thiols do not only function as sulfur acceptors in rhodaneses.

Rhodaneses' substrates are not limited to thiosulfate. In a very recent work, we found that the rhodaneses-like domain DUF442 can also react with GSSH to form the $E S^{0}$ intermediate at $\mathrm{pH} 7.4$ [27]. The $\mathrm{pK}_{\mathrm{a}}$ value of GSSH was determined to be 6.9; therefore, at pH 7.4 it exists mainly as relatively stable deprotonated form $\left(\mathrm{GSS}^{-}\right)$. At protonated form GSSH is prone to release its sulfane sulfur [27]. The rapid reaction of GSSH with DUF442 at pH 7.4 suggests that the DUF442 catalytic pocket propels the protonation of GSSH. Therefore, rhodaneses impel the sulfane sulfur release from a donor substrate via providing a hydrogen bond-sharing microenvironment.

It is noteworthy that the rhodaneses tested herein all show much higher catalytic rates on Reaction 1 than on Reaction 2. This should be caused by the structural difference of acceptors. Cyanide is a much smaller compound than GSH, even smaller than thiosulfate, hence it should be able to enter the pocket and is more accessible to the persulfide group of $E S^{0}$. In addition, other compounds present in biological systems, such as cysteine, homocysteine, and nitric oxide, also can be acceptors. After obtaining sulfane sulfur, they become molecules with important physiological functions. The promiscuity on both donor and acceptor substrates suggests that rhodanese play central roles in sulfane sulfur distribution, and hence are related to various functions of RSS.

\section{Conclusions}

In this study, we reported the 3D structure of rhodanese Rd12 with a $2.47 \AA$ resolution. From the location of its sulfane sulfur atom and activity assay results, we found that Rdl2 catalyzes thiosulfate decomposition via providing a hydrogen bond-sharing microenvironment, in which $\mathrm{S}_{2} \mathrm{O}_{3}{ }^{2-}$ becomes protonated-like. The Arg residue in its active-site loop is essential for Rd12 activity. We also analyzed other rhodaneses including DUF442 and TST and finally proposed a model to explain how they cut off the sulfane sulfur cut off from thiosulfate. Our model completes the catalyzing mechanism of rhodaneses.

Supplementary Materials: The following are available online at https:/ / www.mdpi.com/article/10 .3390 /antiox10101525/s1, Figure S1: LTQ-Orbitrap tandem mass spectrometry analysis of Cys 106 modification in thiosulfate-reacted RDL2. Figure S2: $\mathrm{RS}_{2}$ analysis of unreacted- and thiosulfatereacted rhodanese. Figure S3: Modeled 3D structure of TST. Figure S4: HPLC quantification of $\mathrm{S}_{8}$ produced from decomposition of thiosulfate.

Author Contributions: Conceptualization, H.L. (Huaiwei Liu) and L.X.; methodology, Q.W. and H.L. (Huanjie Li); data cuion, Y.X.; writing—original draft preparation, H.L. (Huaiwei Liu). All authors have read and agreed to the published version of the manuscript. 
Funding: This research was funded by the National Key R\&D Program of China (2018YFA0901200), the National Natural Science Foundation of China (91751207), and State Key Laboratory of Microbial Technology Open Projects Fund (M2021-13).

Institutional Review Board Statement: Not applicable.

Informed Consent Statement: Not applicable.

Data Availability Statement: The 3D structure of Rdl2 has been deposited in PDB with entry 6K6R. Other data is contained within the article or supplementary material.

Conflicts of Interest: The authors declare no conflict of interest.

\section{References}

1. Lau, N.; Pluth, M.D. Reactive sulfur species (RSS): Persulfides, polysulfides, potential, and problems. Curr. Opin. Chem. Biol. 2019, 49, 1-8. [CrossRef]

2. Olson, K.R.; Straub, K.D. The role of hydrogen sulfide in evolution and the evolution of hydrogen sulfide in metabolism and signaling. Physiology 2016, 31, 60-72. [CrossRef]

3. Filipovic, M.R.; Zivanovic, J.; Alvarez, B.; Banerjee, R. Chemical biology of $\mathrm{H}_{2} \mathrm{~S}$ signaling through persulfidation. Chem. Rev. 2018, 118, 1253-1337. [CrossRef] [PubMed]

4. Shen, J.; Walsh, B.J.C.; Flores-Mireles, A.L.; Peng, H.; Zhang, Y.; Zhang, Y.; Trinidad, J.C.; Hultgren, S.J.; Giedroc, D.P. Hydrogen sulfide sensing through reactive sulfur species (RSS) and nitroxyl (HNO) in Enterococcus faecalis. ACS Chem. Biol. 2018, 13, 1610-1620. [CrossRef]

5. Mustafa, A.K.; Gadalla, M.M.; Sen, N.; Kim, S.; Mu, W.; Gazi, S.K.; Barrow, R.K.; Yang, G.; Wang, R.; Snyder, S.H. H 2 S signals through protein S-sulfhydration. Sci. Signal. 2009, 2, ra72. [CrossRef]

6. Dinegar, R.H.; Smellie, R.H.; Mer, V.K.L. Kinetics of the acid decomposition of sodium thiosulfate in dilute solutions. J. Am. Chem. Soc. 1951, 73, 2050-2054. [CrossRef]

7. Rolia, E.; Chakrabarti, C.L. Kinetics of decomposition of tetrathionate, trithionate, and thiosulfate in alkaline media. Environ. Sci. Technol. 1982, 16, 852-857. [CrossRef]

8. Hopfinger, M.; Zischka, F.; Seifert, M.; Kornath, A.J. Preparation and characterization of pure thiosulfuric acid. Z. Anorg. Allg. Chem. 2018, 644, 574-579. [CrossRef]

9. Miaskiewicz, K.; Steudel, R. The structures of thiosulfuric acid $\mathrm{H}_{2} \mathrm{~S}_{2} \mathrm{O}_{3}$ and its monoanion $\mathrm{HS}_{2} \mathrm{O}_{3}{ }^{-}$. Angew. Chem. Int. Ed. 1992, 31, 58-59. [CrossRef]

10. Toohey, J.I.; Cooper, A.J. Thiosulfoxide (sulfane) sulfur: New chemistry and new regulatory roles in biology. Molecules 2014, 19, 12789-12813. [CrossRef] [PubMed]

11. Xin, Y.; Liu, H.; Cui, F.; Liu, H.; Xun, L. Recombinant Escherichia coli with sulfide:quinone oxidoreductase and persulfide dioxygenase rapidly oxidises sulfide to sulfite and thiosulfate via a new pathway. Environ. Microbiol. 2016, 18, 5123-5136. [CrossRef]

12. Shen, J.; Peng, H.; Zhang, Y.; Trinidad, J.C.; Giedroc, D.P. Staphylococcus aureus sqr encodes a type II sulfide: Quinone oxidoreductase and impacts reactive sulfur speciation in cells. Biochemistry 2016, 55, 6524-6534. [CrossRef]

13. Shen, J.; Keithly, M.E.; Armstrong, R.N.; Higgins, K.A.; Edmonds, K.A.; Giedroc, D.P. Staphylococcus aureus CstB is a novel multidomain persulfide dioxygenase-sulfurtransferase involved in hydrogen sulfide detoxification. Biochemistry 2015, 54, $4542-4554$. [CrossRef]

14. Riglar, D.T.; Giessen, T.W.; Baym, M.; Kerns, S.J.; Niederhuber, M.J.; Bronson, R.T.; Kotula, J.W.; Gerber, G.K.; Way, J.C.; Silver, P.A. Engineered bacteria can function in the mammalian gut long-term as live diagnostics of inflammation. Nat. Biotechnol. 2017, 35, 653-658. [CrossRef]

15. Westley, J. Rhodanese. Adv. Enzymol. Relat. Areas. Mol. Biol. 1973, 39, 327-368.

16. Arijs, I.; Vanhove, W.; Rutgeerts, P.; Schuit, F.; Preter, V.D. Decreased mucosal sulfide detoxification capacity in patients with crohn's disease. Inflamm. Bowel Dis. 2013, 19, E70-E72. [CrossRef]

17. Smirnov, A.; Comte, C.; Mager-Heckel, A.M.; Addis, V.; Krasheninnikov, I.A.; Martin, P.R.; Entelis, N.; Tarassov, I. Mitochondrial enzyme rhodanese is essential for $5 \mathrm{~S}$ ribosomal RNA import into human mitochondria. J. Biol. Chem. 2010, 285, 30792-30803. [CrossRef] [PubMed]

18. Chen, Z.; Zhang, X.; Li, H.; Liu, H.; Xia, Y.; Xun, L. The complete pathway for thiosulfate utilization in Saccharomyces cerevisiae. Appl. Environ. Microb. 2018, 84, e1241-18. [CrossRef]

19. Libiad, M.; Motl, N.; Akey, D.L.; Sakamoto, N.; Fearon, E.R.; Smith, J.L.; Banerjee, R. Thiosulfate sulfurtransferase-like domaincontaining 1 protein interacts with thioredoxin. J. Biol. Chem. 2018, 293, 2675-2686. [CrossRef] [PubMed]

20. Libiad, M.; Sriraman, A.; Banerjee, R. Polymorphic Variants of Human Rhodanese Exhibit Differences in Thermal Stability and Sulfur Transfer Kinetics. J. Biol. Chem. 2015, 290, 23579-23588. [CrossRef] [PubMed]

21. Gliubich, F.; Gazerro, M.; Zanotti, G.; Delbono, S.; Bombieri, G.; Berni, R. Active site structural features for chemically modified forms of Rhodanese. J. Biol. Chem. 1996, 271, 21054-21061. [CrossRef] [PubMed] 
22. Spallarossa, A.; Donahue, J.L.; Larson, T.J.; Bolognesi, M.; Bordo, D. Escherichia coli GlpE is a prototype sulfurtransferase for the single-domain Rhodanese homology superfamily. Structure 2001, 9, 1117-1252. [CrossRef]

23. Cipollone, R.; Ascenzi, P.; Visca, P. Common themes and variations in the Rhodanese superfamily. IUBMB Life 2007, 59 , ra72. [CrossRef] [PubMed]

24. Hess, D.C.; Myers, C.L.; Huttenhower, C.; Hibbs, M.A.; Hayes, A.P.; Paw, J.; Clore, J.J.; Mendoza, R.M.; Luis, B.S.; Nislow, C.; et al. Computationally driven, quantitative experiments discover genes required for mitochondrial biogenesis. PLoS Genet. 2009, 5, e1000407. [CrossRef]

25. Niu, W.; Li, Z.; Zhan, W.; Iyer, V.R.; Marcotte, E.M. Mechanisms of cell cycle control revealed by a systematic and quantitative overexpression screen in S. cerevisiae. PLoS Genet. 2008, 4, e1000120. [CrossRef] [PubMed]

26. Luo, G.X.; Horowitz, P.M. The sulfurtransferase activity and structure of Rhodanese are affected by site-directed replacement of Arg-186 or Lys-249. J. Biol. Chem. 1994, 269, 8220-8225. [CrossRef]

27. Li, H.; Liu, H.; Chen, Z.; Zhao, R.; Wang, Q.; Ran, M.; Xia, Y.; Hu, X.; Liu, J.; Xian, M.; et al. Using resonance synchronous spectroscopy to characterize the reactivity and electrophilicity of biologically relevant sulfane sulfur. Redox Biol. 2019, $24,101179$. [CrossRef]

28. Xia, Y.; Li, K.; Li, J.; Wang, T.; Gu, L.; Xun, L. T5 exonuclease-dependent assembly offers a low-cost method for efficient cloning and site-directed mutagenesis. Nucleic Acids Res. 2018, 47, e13. [CrossRef]

29. Xia, Y.; Chu, W.; Qi, Q.; Xun, L. New insights into the QuikChange ${ }^{\mathrm{TM}}$ process guide the use of Phusion DNA polymerase for site-directed mutagenesis. Nucleic Acids Res. 2015, 43, e12. [CrossRef]

30. Li, H.; Li, J.; Lü, C.; Xia, Y.; Xin, Y.; Liu, H.; Xun, L.; Liu, H. FisR activates $\sigma^{54}$-dependent transcription of sulfide-oxidizing genes in Cupriavidus pinatubonensis JMP134. Mol. Microbiol. 2017, 105, 373-384. [CrossRef]

31. Sörbor, B.H. Rhodanese. Acta Chem. Scand. 1953, 7, 1137-1145.

32. Libiad, M.; Yadav, P.K.; Vitvitsky, V.; Martinov, M.; Banerjee, R. Organization of the human mitochondrial $\mathrm{H}_{2} \mathrm{~S}$ oxidation pathway. J. Biol. Chem. 2014, 289, 30901-30910. [CrossRef] [PubMed]

33. Kamyshny, A., Jr.; Goifman, A.; Gun, J.; Rizkov, D.; Lev, O. Equilibrium distribution of polysulfide Ions in aqueous solutions at $25^{\circ} \mathrm{C}$ : A new approach for the study of polysulfides' equilibria. Environ. Sci. Technol. 2004, 38, 6633-6644. [CrossRef] [PubMed] 